\title{
The epidermal growth factor receptor/Erb-B/HER family in normal and malignant breast biology
}

\author{
SUZANNE A. ECCLES* \\ The Institute of Cancer Research, Surrey, UK
}

\begin{abstract}
The EGFR/Erb-B receptor tyrosine kinases each play distinct and complementary roles in normal breast development. The four receptors form both homodimers and heterodimers in response to binding by ligands which show selectivity for one or more of the receptors (except Erb-B2). Together with the additional flexibility generated by the formation of different dimer pairs, these signalling networks play key roles in directing a variety of both autocrine and paracrine cellular responses. Complex two-way interactions between mammary epithelial cells and the surrounding stroma direct proliferation, duct formation, branching and terminal differentiation during puberty, pregnancy and lactation, with each receptor and ligand fulfilling distinct roles. Caricatures of the normal role of EGFR/Erb-B signalling resulting in aberrant cellular responses are seen in breast cancers, where over-expression and/or (less commonly) mutation of one or more of the receptors results in enhanced cell proliferation, motility, release of proteases and angiogenic factors. Given their importance in tumour progression and their links with resistance to chemotherapy and anti-endocrine therapy, Erb-B receptors (most notably Erb-B2) have been exploited as therapeutic targets. Monoclonal antibodies (e.g. trastuzumab, pertuzumab) and small molecule tyrosine kinase inhibitors (e.g. lapatinib, afatinib) have shown significant clinical responses in some breast cancer subtypes. Additional approaches include targeted toxins or drugs, peptide vaccines, immunRNase and chaperone inhibitors to deplete Erb-B2 protein levels. Greater understanding of the full spectrum of Erb-B-mediated signalling pathways and their misregulation in breast cancer will provide additional strategies to control malignant progression.
\end{abstract}

KEY WORDS: $E G F R, c-E r b-B 2, c-E r b-B 3, c-E r b-B 4$, cancer

\section{The EGFR/ERB-B/HER family}

The epidermal growth factor receptor (EGFR) and its close relatives HER2/c-Erb-B2, Erb-B3 and Erb-B4 are type 1 transmembrane receptor tyrosine kinases (RTK) with key roles in embryonic development, tissue renewal/repair and cancer. A great deal has been learned about their structure, signalling pathways and aberrations linked to malignant transformation since the explosion of interest in this family in the 1980's.

\section{Early discoveries}

EGFR, a 170kDa glycoprotein, was the first member of the family to be identified as the receptor for a 'growth factor' (EGF) which regulated eyelid opening in mice, and as the binding partner for radiolabelled EGF on fibroblast cell membranes. Subsequently, EGFR was found to have kinase activity when stimulated with ligands and to be capable of phosphorylating tyrosine residues on both itself and downstream targets. Even before EGFR was identi- fied, there were early indications that EGF (then termed epithelial growth factor, even though it is a mitogen for mesenchymal cells too) could be important in breast development as it stimulated growth of mouse mammary gland explants. The role of EGFR was later proved by showing impaired mammary gland development in mice harbouring EGFR mutations (Cohen, 1997).

\section{Structure and function}

Erb-B signalling comprises a complex network with an 'input' (ligand-receptor) layer, an intermediate signalling core processing

Abbreviations used in this paper: ADAM, a disintegrin and metalloproteinase; AREG, amphiregulin; BTC, betacellulin; EGF(R), epidermal growth factor (receptor); EREG, epiregulin; ER, oestrogen receptor; HB-EGF, heparin binding EGF; MEC, mammary epithelial cells; MMP, matrix metalloprotease; NRG, neuregulin(heregulin); RTK, receptor tyrosine kinase; (SM)TKI, (small molecule) tyrosine kinase inhibitor; TEB, terminal end bud; TGFo, transforming growth factor alpha; TN(BC), triple negative (breast cancer).

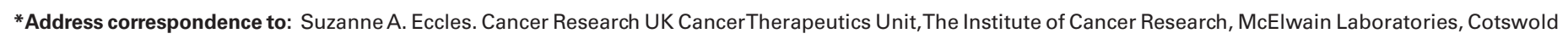
Rd, Belmont, Sutton, Surrey SM2 5NG, UK. Tel: +44(0)208-722-4210. Fax: +44(0)208-722-4134. e-mail: Sue.Eccles@ icr.ac.uk - web: http://www.icr.ac.uk 
level and an 'output' layer of transcriptional regulation and ultimately cellular responses (Citri and Yarden, 2006).

All Erb-B receptors consist of an extracellular domain which binds ligands (except in the case of Erb-B2), a transmembrane region and a cytoplasmic domain with kinase activity. Although there are 10 possible combinations of Erb-B dimers, not all are fully biologically active. Erb-B2 has no known ligands, but is the preferred partner of all family members, due to an intrinsically extended interaction loop rendering it constitutively available for dimerisation. Erb-B2 can stabilise EGFR in a conformation that potentiates dimerisation and phosphorylation in the absence of ligand and alters endocytosis and intracellular trafficking. Alternatively, at least partial transactivation of EGFR can be achieved by ligand-independent intracellular mechanisms, such as G protein-coupled receptor (GPCR) stimulation of Src or elevated calcium levels (Prenzel et al., 2000). Finally, the receptors interact with, and are modulated by, steroid hormone receptors and co-receptors. Erb-B3 was generally accepted to be kinase dead due to the lack of several key functional residues including the catalytic base aspartate, but a recent paper suggests that it nevertheless retains the ability to transphosphorylate its own intracellular domain (Shi et al., 2010). In any event, it can certainly form a very active signalling complex with all other EGFR RTK, especially Erb-B2. There is a high degree of homology in the kinase domain of the four receptors $(59-81 \%)$ but more divergence in the $\mathrm{C}$-terminal domains (only $11-25 \%$ identity). In addition to cross-talk between members of the EGFR/Erb-B family, there is evidence for significant interactions with other RTK such as c-MET and IGF-1R, and it is possible that such alternative signalling pathways are linked to resistance to targeted therapies (Jin and Esteva, 2008). Erb-B receptors also integrate signals from the extracellular microenvironment by forming macromolecular clusters with integrins and tetraspanins in specialised membrane microdomains (Alexi et al., 2011)

\section{Ligands}

There are up to 13 recognised ligands of the EGFR family: EGF itself, heparin-binding (HB)-EGF, transforming growth factor (TGF) $\alpha$, amphiregulin (AREG) epiregulin (EREG), epigen (EPG), betacellulin (BTC) and neuregulins (NRG) 1-6 (also known as heregulins), which have multiple splice variants. EGF and TGF $\alpha$ are the key EGFR binding ligands, BTC can bind and activate all receptors, and the NRGs have a preference for Erb-B3 and Erb-B4. All EGF family ligands exist as membrane-anchored precursors and are cleaved by metalloproteases (mainly ADAMs) resulting in ectodomain shedding and the release of soluble factors. The cleaved products, particularly of HB-EGF, have been implicated in transactivation of adjacent Erb-B receptors, and the remaining intracellular carboxyterminal fragments may have additional intracellular signalling functions (Higashiyama et al., 2008). The EGFR ligand shedding and subsequent receptor activation can be stimulated by many factors, including cytokines which bind G-protein couple receptors, activating PKC and MAPK signalling pathways (in the so-called triple membrane-passing signal mechanism) or via Wnt ligands binding Fzd receptors. Uncleaved, membrane-bound ligands can also stimulate adjacent cells via a juxtacrine mechanism which may be particularly important in epithelial-stromal communication. There is evidence that different ligands can promote specific patterns of EGFR phosphorylation and dictate the duration of signalling events and divergent cellular responses. For example, TGF $\alpha$ and AREG are more potent stimulators of motility and invasion than EGF. This is reportedly due to sustained activation of PLC $\gamma$ and MAPK by the former ligands, whereas EGF promotes more rapid ubiquitination and degradation of EGFR.

\section{Downstream signalling}

Ligand binding induces conformational rearrangements of the receptors to expose the interaction loop, promoting association of both homodimers and heterodimers, followed by internalisation and/or phosphorylation events. The phosphorylated (activated) receptors act as docking points for a number of direct substrates and/or adaptor proteins. Systematic profiling of phosphotyrosine interaction sites has shown that the four receptors have specific patterns of binding partners, although each may be recruited to more than one site, albeit with different affinities or kinetics. For example, binding of Shc, Grb2 or PI3K to Erb-B2 is influenced by the mode of activation and the dimerisation partner (Schulze et al., 2005). This degree of flexibility therefore allows differential responses to external stimuli in different microenvironmental contexts and the integration of stimuli into co-ordinated cellular functions.

STAT5 was identified as a direct binding partner of EGFR and Erb-B4, and this interaction is required in the breast during lactation (Schulze et al., 2005). Interestingly, EGFR and Erb-B4, the only fully functional receptors (in contrast to Erb-B2 and Erb-B3) have the greatest number of interactors and probably fulfil similar functions in different cellular contexts in response to their preferred ligands (EGF family and NRGs respectively).

Erb-B3 is activated primarily by NRG-1 and -2 and is a strong activator of the PI3 kinase pathway, having six binding sites for the p85 regulatory subunit. The PI3 kinase pathway is a pivotal point in cell signalling (mainly via AKT and mTOR) regulating cell size, metabolism, survival and proliferation. Negative regulation of pro-apoptotic and growth inhibitory pathways is mediated via FOXO transcription factors and GSK3 $\beta$. There are additional links to promotion of motility via Rac and Rho, and angiogenesis via activation of HIF-1 $\alpha$.

In summary, the major signalling pathways activated by EGFRErb-B receptors are mediated by PI3 kinase, Ras-Raf (MAPK), JNK, PLC $\gamma$ and result in a plethora of biological functions. Although initially termed "growth" factors, the ligands induce not only cell proliferation but also alter adhesion and motility and protect against apoptosis at the cellular level, and promote invasion and angiogenesis at the physiological level. Given that these signalling systems are critical in development, it is not surprising that their activation should result in multiple co-ordinated cell- and tissue-level responses in normal cells, but these are subverted by overexpression/misregulation in pathological processes such as cancer.

\section{Roles in normal breast development}

Much of our understanding of the functions of the Erb-B family in development has come from rodent models. EGFR is of course best known as the epidermal growth factor receptor and is primarily responsible for maintaining skin and squamous epithelia. The other three family members are important for the development and maintenance of the cardiovascular and nervous systems, but also play complementary roles in breast development. Most of the Erb-B family receptors and their ligands are expressed in the mammary gland at some time during development, maturation and involution (Fig. 1). The precise and co-ordinated roles of the receptors 
and their ligands are to some extent confounded by spatial and temporal complexities, a degree of redundancy, and many layers of regulation. Nevertheless, those functions that have been elucidated have proved informative for the better understanding of consequences of their misregulation in the caricatures of cancer.

The mammary gland is an unusual organ in that most of its development occurs not in embryonic development, but at puberty, stimulated by steroid hormones. Interestingly, the rudimentary embryonic ductal branching, and all subsequent phases of epithelial differentiation are orchestrated by signals from the surrounding stroma; indeed mammary epithelial cells can be completely redirected (e.g. toward salivary gland morphology and function) by placing them in association with mesenchymal cells from different tissues.

The earliest phases of breast development are oestrogen independent. In adolescence, oestrogen and oestrogen receptor (ER) $\alpha$ induce the next stage of branching, and in the adult progesterone

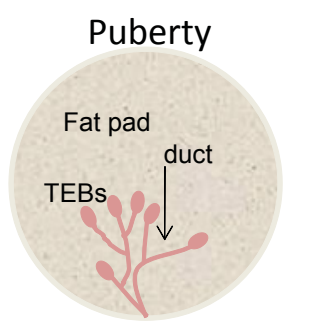

\section{Signalling Biological responses}
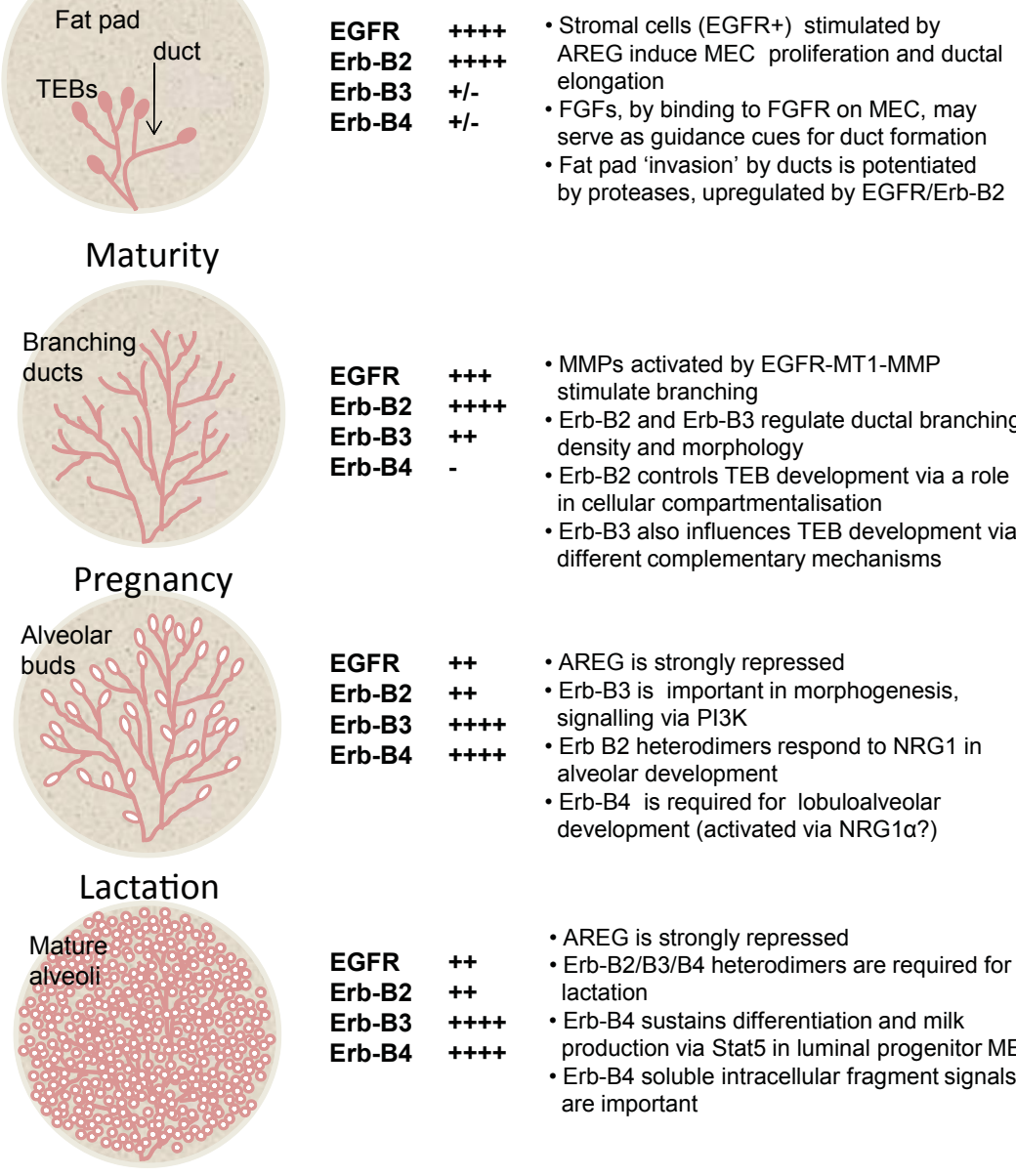

Fig. 1. Differential roles of EGFR/Erb-B receptors and ligands during normal mammary gland development and maturation. The Figure illustrates the time- and differentiationdependent expression of the four Erb-B receptors and key ligands at puberty and during adult breast maturation, pregnancy and lactation. Their contrasting roles in ductal outgrowth, terminal end-bud (TEB) development, alveolar maturation and lactation are shown, and differential expression in epithelial and stromal cells is highlighted.
(PRG) plays a key role. The major contribution of Erb-B receptors is during puberty, pregnancy and lactation, when the steroid hormones upregulate production of many growth factors, including those of the EGF family.

\section{EGFR signalling and the role of proteolytic regulation of ligands}

Both EGF and TGF $\alpha$ in vitro and under certain circumstances in vivo can stimulate growth of mammary epithelium and ductal differentiation. However, careful genetic knockdown, array and in situ hybridisation studies have identified epithelial AREG as the main (if not the only) physiologically relevant ligand in vivo. What is more, it is strongly induced by oestrogens. Mammary morphogenesis has been shown to require release of soluble AREG from ductal epithelial cells, its activation of EGFR on adjacent stromal cells, (particularly those immediately adjacent to developing ductal end buds) and then reciprocal inductive signals back to the epithelium (Sternlicht and Sunnarborg, 2008) (Fig. 2).

ADAM17 null mice show the same developmental defects as those lacking TGF- $\alpha$, or HB-EGF, suggesting that this protease is primarily responsible for their processing and cleavage (Sahin et al., 2004). Further evidence of its physiological importance in mammary development was provided by its appropriate localisation in the gland (although this was also the case for many other ADAMs). However, the reciprocal lack of its sole inhibitor (TIMP3) in TEBs suggests that ADAM17 would be active in areas of active ductal development.

The means by which EGFR-activated stromal cells induce mammary epithelial development has also been intensively studied but it still not fully elucidated. Given the multiplicity of cellular responses required (cell proliferation, stromal 'invasion', of ducts, terminal differentiation) it is likely that many simultaneous cellular responses are elicited. MT1-MMP (MMP14) is enriched in stroma surrounding TEBs and its activity, like that of ADAM17, would be enhanced by the local downregulation of TIMP3. MMP14 may stimulate ductal branching by activating MMP2 and degrading collagen 1. However it is membrane-bound and could only influence epithelial cells indirectly. Structural defects in TEBs in Erb-B2 ${ }^{-/}$mammary epithelium may contribute to the observed deficiency in ductal penetration into the fatpad, secondary to misregulation of matrix metalloproteinases, since branching morphogenesis requires MMP-2, and MMP-3 promotes secondary and tertiary branching. Another potential contributory mechanism is signalling via FGFR2 on mammary epithelial cells stimulated by stromal FGF10 providing both mitogenic stimuli and guidance cues for ductal development (Sternlicht and Sunnarborg, 2008) (Fig. 2).

\section{Other Erb-B family members: additional roles in later mammary differentiation}

AREG becomes strongly repressed during pregnancy and lactation and EGFR is not required for alveolar development. Erb-B2 in the epithelium is required for ductal outgrowth and TEB development and its functional partner is thought to be Erb-B3, 
since knock-out of either gene results in similar abnormalities in these processes.

Erb-B3 appears when mammary glands mature and Erb-B4 is only expressed during pregnancy and lactation. In Erb-B3-/- mice, there was a decrease in the size of TEBs but increases in branch density and the number of TEBs. This was associated with an increase in apoptosis but no change in cell proliferation rates in TEBs. The major signalling pathway activated by Erb-B3 in this context seems to be PI3 kinase (Stern, 2008). Nrg3polymorphisms can also result in abnormalities in rodent mammary gland development, also likely via activation of Erb-B3. Thus Erb-B3 plays a key role in regulating morphogenesis of mammary epithelium (Fig. 1).

During pregnancy and lactation, Erb-B2, in association with its partners and in response to neuregulins, is required for alveolar differentiation and milk protein production. Erb-B4 is essential for lobuloalveolar development and for maintaining lactation reportedly via Stat5a. The ligand(s) responsible for activating Erb-B4 in these processes have not been finally elucidated, although NRG/ HRG1 $\alpha$ has been implicated. Most of Erb-B4's functions in the mammary gland seem to be mediated by a soluble intracellular fragment (4ICD). This fragment can localise in mitochondria and nuclei, eliciting different functional responses in cells. The $180 \mathrm{kDa}$ membrane-bound Erb-B4 is cleaved by ADAM17, releasing a 120 $\mathrm{kDa}$ ligand-binding ectodomain and an $80 \mathrm{kDa}$ transmembrane peptide (m80) with kinase activity (Blobel et al., 2009). The latter

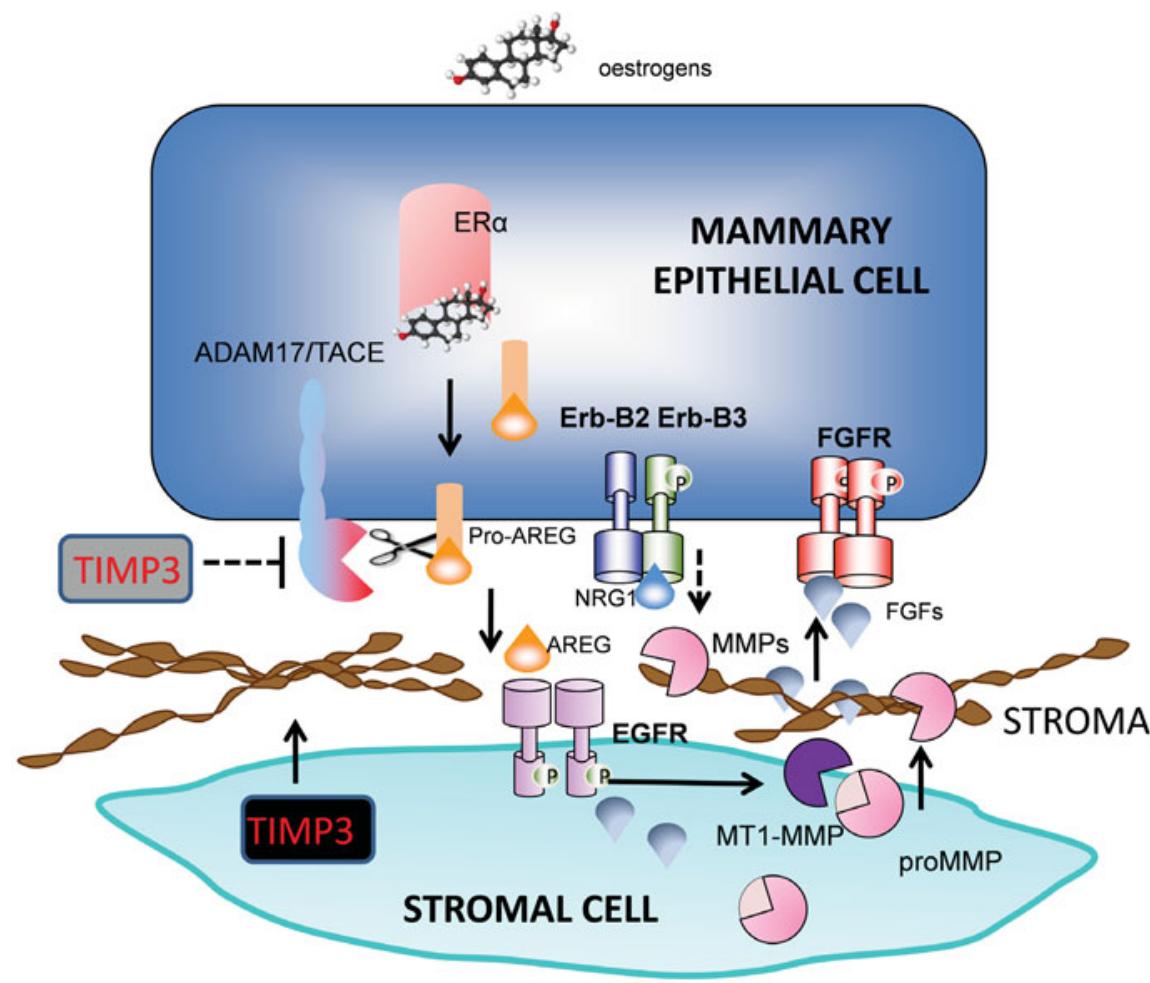

Fig. 2. EGFR/Erb-B signalling linked to epithelial cell-stromal cell interactions in ductal development in the mammary gland. The Figure illustrates the reciprocal interactions between stromal cells and mammary epithelial cells (MEC) during normal development. ADAM sheddases, regulated by oestrogens, release ligands such as AREG which stimulate EGFR on neighbouring stromal cells. Additional proteases (e.g MMP2 activated by MT1-MMP) release growth factors which reciprocally stimulate MECs to proliferate. MMPs are also required for ductal 'invasion' into the fat pad. Adapted from (Sternlicht and Sunnarborg, 2008). fragment is released from the membrane by presenilin-dependent $\gamma$-secretase cleavage. Cleavage can be stimulated by ligand binding (generally HRG, HB-EGF or BTC) or simply in response to Erb-B4 overexpression.

Nuclear 4ICD in secretory mammary epithelium signalling via Stat5a is thought to be the major driver of lactation since Stat5a transcriptionally regulates $\beta$-casein and whey acidic protein (WAP) promoters. The proposed mechanism is as follows: Erb-B4 when activated becomes phosphorylated at Y964, providing a docking site for Stat5a SH2 domains. The following regulated intra-membrane proteolysis (RIP) previously described results in liberation of the 4 ICD-Stat5a complex and its translocation to the nucleus. It has been suggested that the 4ICD simply acts as a Stat5a chaperone, but may also serve as a regulator of transcription (Jones, 2008) indeed have intrinsic independent transactivation activity. The 4ICD fragment also functions as a selective $\mathrm{ER} \alpha$ co-activator since it regulates expression of PGR, SDF-1 and Erb-B4 itself. This involves ER $\alpha$ recruitment not to canonical ERE sites but to AP-1 sites in a complex with c-Jun (DeNardo et al., 2007). In contrast, some of the apparently contradictory findings, especially in relation to breast cancer biology.

\section{Mutations and mechanisms of activation}

Deregulation of Erb-B signalling pathways has been described in many cancers, including breast, linked to a multiplicity of molecular mechanisms including overexpression due to gene amplification or epigenetic mechanisms, activating mutations of the receptors themselves or activation induced by autocrine/paracrine ligands. EGFR is frequently activated by heterodimerisation with other TKR, and also heterologous receptors such as GPCR via Src. Recently a novel mechanism of EGFR signalling has been suggested: EGFinduced translocation to the nucleus associated with $\mathrm{p}-\mathrm{Ty}$ r-1068 and indirect binding to DNA via STAT3 enabling EGFR to act as a transcriptional regulator of genes such as cyclin D1 and iNOS - discussed in (Burness et al., 2010).

\section{Links to breast cancer}

All of the four receptors are overexpressed to varying degrees in breast cancer, with their prominence being in rank order Erb-B2>EGFR>ErbB3>Erb-B4. Many ligands, including NRG splice variants are also overexpressed, suggesting the possibility of autocrine signalling, although the combined measurement of EPG and NRG4 were the strongest predictors of relapse free interval and overall survival (Mclntyre et al., 2010).

\section{EGFR}

Many early reports of expression/overexpression of EGFR and its ligands in breast cancer and links to prognosis were contradictory as they were largely based on immunohistochemical data and did not necessarily address the activation state of the signalling pathway. More 
recent gene expression analyses and also functional studies have clarified the key role that EGFR may play in specific breast cancer subsets (Foley et al., 2010).

Mutations in EGFR are rare in breast cancers but it is amplified in some cases (e.g. metaplastic subtype) (Burness et al., 2010) and is also highly expressed (with or without amplification) in basal breast cancers, a subset of triple negative breast cancers (TNBC; i.e. lacking ER, PGR or Erb-B2). TNBCs represent $10-17 \%$ of all breast cancers, are more common in certain non-Caucasian ethnic groups (e.g. those of African descent) and tend to occur at less than 50 years of age. These cancers are also generally of high grade and show distinct patterns of metastasis; notably visceral, liver and brain involvement leading to particularly poor prognosis (Dawson et al., 2009). EGFR expression was found to be higher in patients with nodal or distant metastases than in those without (Sutton et al., 2010). Also, TGF $\alpha$ and NRG2 $\beta$ and the proteases responsible for their cleavage and activation are frequently overexpressed in ER- cancers (suggesting autocrine signalling) whereas AREG is expressed in ER+ cancers and may rather promote paracrine activation via the stroma (Foley et al., 2010).

TNBC is particularly prevalent in women carrying a $B R C A 1$ mutation and EGFR overexpression is found in $67 \%$ of $B R C A 1$ related cancers vs $\sim 18 \%$ of sporadic cancers. Using human mammary epithelial cell (hMEC) cultures it was shown that even partial suppression of BRCA1 function (using RNAi) could induce EGFR expression and an increase in EGFR+ cancer stem-like cells, suggesting that this receptor could provide a growth advantage at early stages of transformation. Treating (MMTV-Cre) BRCA $1^{\text {flox/flox }}$ p53 ${ }^{+/-}$transgenic mice with the EGFR inhibitor erlotinib significantly increased the latency period before mammary tumours developed, although this was limited to ER- and not ER+ subtypes (Burga et al., 2011). These data suggest that early intervention with EGFR inhibitors could be beneficial to BRCA1 mutation carriers in a preventive setting. However, in established cancers, clinical trials to date have not shown major responses in unselected patient populations (Burness et al., 2010).

Inflammatory breast cancer is particularly aggressive, with the majority of patients having disease in their lymph nodes and over one third with distant metastases at the time of diagnosis. It is characterised by loss of $\mathrm{ER}$, activation of NF- $\mathrm{kB}$, overexpression of RhoC GTPase (resulting in a highly angiogenic phenotype) and a hyperactivated MAPK signalling path which has been linked to overexpression of EGFR and Erb-B2 (Van Laere et al., 2007).

EGFR has also been implicated as a key player in the mitogenic and motogenic effects mediated by the HGF-c-MET signalling axis in breast cancer. HGF and/or c-MET expression increase with tumour progression and each is independently associated with poor prognosis. Cross-talk between these RTK has been identified in several tumour types, with HGF able to transactivate EGFR and conversely EGFR ligands activating c-MET via intracellular signalling pathways. EGFR inhibitors have been shown to attenuate HGF-mediated proliferation, motility and invasion of several breast cancer cell lines in vitro.

\section{Erb-B2}

$\mathrm{Neu}$, the rat homologue of Erb-B2, was first identified in a chemically-induced neuroblastoma and shown to be similar to a retroviral oncogene ( $v$-Erb-B) related to EGFR. Multiple subsequent studies identified Erb-B2/HER2 in 20-30\% of breast cancers, where it is associated with poor prognosis, although it is an early event occurring in over half of in situ carcinomas. Interestingly, an Erb-B2 subtype clearly emerged from a genetic analysis of breast cancer which identified five molecular signatures with distinct biological properties (Sorlie, 2004). Breast cancers may express between 25-50 copies of the ERB-B gene resulting in up to 2 million receptors per cell. This differential provides a relatively tumour-selective therapeutic target, as levels are absent or low in most normal adult tissues. One exception is the heart, which may explain some of the cardiomyopathies seen with Erb-B targeted therapies, particularly when they were administered with anthracyclines, which is no longer a recommended combination (Procter et al., 2010).

Erb-B2-positive cancers have some unique biological properties, including increased sensitivity to doxorubicin (perhaps because the HER2 gene is co-amplified with topisomerase 2, the target of doxorubicin) and relative refractoriness to anti-endocrine agents (partly due to an inverse relationship between Erb-B2 and ER $\alpha$ expression levels). It has been suggested that Erb-B2+ breast cancers may be especially prone to post-surgical recurrences due to their proliferative responses to growth factors in wound fluid, and that this could be prevented by trastuzumab. However, only a subset of Erb-B2+ breast cancers responds to trastuzumab, suggesting additional levels of complexity. Recently, more detailed analyses have revealed not only genetic heterogeneity within Erb-B2+ tumours, but also significant epigenetic influences. Those that express high levels of hypoxia-regulated genes show characteristics of basal cancers, and those without behaved more like luminal cancers, showing that even oncogenic drivers such as Erb-B2 are susceptible to modulation by the host microenvironment (Gatza et al., 2011).

\section{Erb-B3}

In mouse mammary carcinoma models induced by PyVMT or mutated or overexpressed neu, Erb-B3 is frequently activated and found in association with Erb-B2, again attesting to the effective association of this specific dimerisation partnership. These tumours are inhibited by the EGFR inhibitor gefitinib and the dual inhibitor lapatinib: response has been associated with inhibition of Erb-B3 and AKT phosphorylation. In contrast resistance has been linked with a de novo point mutation in Erb-B2. In a panel of six Erb-B2overexpressing human tumour cell lines, Erb-B3 knockdown by RNAi was as effective as Erb-B2 knockdown at inhibiting proliferation in vitro, and xenograft tumour growth in vivo, whereas EGFR expression was dispensable. Preferential phosphorylation of Erb-B3 was also seen in Erb-B2+ human breast cancers, suggesting a pivotal role for Erb-B3 in Erb-B2-driven tumours (Stern, 2008).

Erb-B3 is overexpressed in around $10 \%$ of breast cancers, and its common association with Erb-B2 makes its specific role difficult to determine. Since it has no intrinsic kinase activity, it must function solely as a key dimerisation partner, although it can become phosphorylated by other receptors. The phosphorylated form strongly activates the PI3 kinase pathway as it contains multiple binding sites for the $\mathrm{p} 85$ regulatory subunit. In some studies Erb-B3 expression seemed to correlate with ER positivity and was associated with longer overall survival. There is a stronger association with poor prognosis when the gene is amplified (suggesting active genetic selection), although a role for co-amplified genes cannot be excluded. There are thought to be important but poorly understood roles for nuclear localization and secreted isoforms such as p85 soluble Erb-B3, akin to the p95Erb-B2 ECD. The 
disparate results reported could also be related to the subcellular localisation of Erb-B3 and its activation status, which in turn are regulated by ligand availability.

\section{Erb-B4}

There are contradictory data on the role of Erb-B4 in breast cancer since both positive and negative associations with prognosis have been described; also the full-length and cleaved (4ICD) splice variants may have different functions (Sundvall et al., 2008). It is reportedly associated with luminal A breast cancer subtypes (which have a better prognosis than other groups) perhaps linked to its role in differentiation. It is also generally associated with positive ER status and hence has been predicted to be oestrogen regulated. In support of this is the fact that its promoter contains three possible oestrogen response element half-sites and oestrogen recruits $E R \alpha$ to one of these sites.

Inhibition of Erb-B4 expression can inhibit the proliferation of ER+ breast carcinoma cell lines, suggesting a growth promoting effect that is ER $\alpha$-dependent and reliant upon cross-talk between these two signalling pathways. Other Erb-B family members also show reciprocal interactions, with mechanisms that include phosphorylation of ER $\alpha$ or its co-activators, linked to ER $\alpha$-induced upregulation of Erb-B ligands and a fostering of autocrine signalling loops. However, the Erb-B4 mechanism involving interactions between a cell surface and a nuclear receptor is unique.

Paradoxically, stimulation of ER+ breast cancer cells with ErbB4 ligand, however, can result in cell death, even though it is also dependent on proteolytic release of 4ICD. It has been proposed that, since this activity is independent of nuclear localisation, it may be the result of 4ICD activity in the cytosol. 4ICD contains motifs similar to pro-apoptotic $\mathrm{BH} 3$ proteins and localises in mitochondria and the endoplasmic reticulum; also its anti-tumour activity is attenuated by the caspase inhibitor zVAD, suggesting that it is a bone fide apoptosis inducer. In support of this function, an association between cytosolic expression of 4ICD and apoptotic cells was noted in human breast cancers (Jones, 2008). A unifying hypothesis to explain these disparate functions has been proposed whereby in early stages of breast cancer development, ligand (mainly $\mathrm{HRG} \alpha$ ) activation of Erb-B4 generates nuclear 4ICD. ER+ cells have a growth advantage and a 4ICD-dependent autocrine loop develops, shifting from a Stat5 co-activator of differentiation to an ER $\alpha$ coactivator driving proliferation. At later stages both ER $\alpha$ and Erb-B4 may be lost, perhaps being redundant in the face of additional even stronger oncogenic drivers (Jones, 2008). These intriguing possibilities (and their therapeutic implications) are currently being actively investigated.

These varying associations between the Erb-B receptors and breast cancer biology are interesting as they may echo their contrasting roles in mammary gland development: promoting cell proliferation/'invasion' of ductal epithelial cells into the mammary fat in the case of EGFR/Erb-B2/3 and a function in epithelial differentiation for Erb-B4 (Stern, 2008). It may be that subsets of precursor cells, representative of a specific stage of breast development become trapped in that phenotype, unresponsive to normal regulatory cues.

\section{Ligands and downstream signalling pathways in breast cancer}

Given the importance of the ADAM17-AREG/TGF $\alpha$-EGFR axis in normal mammary development, it is not surprising that all of these elements-and those that they regulate such as additional proteases and growth factor signalling pathways - are misregulated in breast cancers. ADAM17, AREG and TGF $\alpha$ are frequently upregulated, with co-expression of TGF $\alpha$ and EGFR being associated with particularly poor prognosis. Antisense suppression of AREG reduced the tumorigenicity of immortalised human mammary epithelial cells and prevented EGFR becoming activated in response to exogenous ligands (Ma et al., 2010).

In an interesting series of experiments with human mammary epithelial cells at different stages of transformation from immortalised - premaligant - tumorigenic, it was shown that progression was associated with upregulation of AREG and TGF $\alpha$, rendering them independent of exogenous EGF. In 3D cultures, reversion to a non-malignant phenotype was achieved by inhibitors of proteolytic activity or EGFR, suggesting an autocrine MMP/ADAM-dependent EGFR activation pathway. Similar effects were achieved by ADAM17 siRNA(Kenny and Bissell, 2007), suggesting that this protease may be a good therapeutic target in EGFR-dependent breast cancers.

\section{Angiogenesis, invasion and metastasis}

All solid tumours require the ability to co-opt host vasculature and/or stimulate de novo angiogenesis in order to grow progressively. The newly formed vasculature is leaky and provides a ready conduit for haematogenous dissemination. One of the major angiogenic growth factors is VEGF, which is upregulated not only by hypoxia, but also via the Erb-B oncogenes, likely via the PI3K-AKT signalling pathway. Erb-B2 and EGFR overexpression tends to correlate with increased levels of VEGF A (and also lymphangiogenic cytokines VEGF $C$ and D) and in some cases with higher microvessel density.

Hypoxia itself is a known adverse prognostic indicator, and many HIF-responsive genes (such as MMPs, CXCR4, c-MET, LOX) are implicated in angiogenesis and metastasis. In the case of the G-protein-coupled chemokine receptors such as CXCR4, and its ligand CXCL12/SDF-1 $\alpha$, their expression and activation has also been linked to site-selective metastasis. Erb-B2 and CXCR4 levels tend to correlate in breast cancers, and the former is reported to enhance CXCR4 expression and to inhibit ligand-induced degradation. Interestingly, inhibition of CXCR4 expression suppressed Erb-B2-mediated malignant potential suggesting a mechanistic linkage between the two signalling axes.

In order to metastasise, cells must detach from underlying extracellular matrix (ECM), acquire the ability to survive under these anchorage independent conditions, and demonstrate the ability to invade surrounding tissues and basement membranes. Invasion requires a motile phenotype and, in most cases, is potentiated by proteolytic activity, although protease-independent 'amoeboid' motility has also been described. An early manifestation of breast cancer is the ability of transformed but premalignant cells to proliferate within the ductal lumen, away from their natural ECM niches. Detachment usually induces downregulation of EGFR (and cell death) but this can be overcome by Erb-B2, which stabilises EGFR and $\beta 1$ integrin via Erk-Sprouty2 signalling and a lowered affinity of the heterodimers for $\mathrm{c}-\mathrm{Cbl}$, which normally promotes EGFR trafficking to lysosomes (Grassian et al., 2011).

Erb-B2 and EGFR are also recognised as activating key signal- 
ling pathways promoting cell motility; indeed EGFR ligands are very potent chemotactic factors, stimulating rapid migration along concentration gradients. AIB1/SRC3 is associated with breast invasion and metastasis. A splice variant (SRC-3 $\triangle 4$ ) promotes NRG-Erb-B2 mediated motility, co-operating with Erb-B2 to induce progression of DCIS to invasive ductal carcinoma. Erb-B2 reportedly selectively promotes MDA-MB-468 migration mediated by EGF via phosphorylation of tyr $\mathrm{r}^{1248}$ and a transient activation of PLC $\gamma$. Others have implicated Tyr ${ }^{1227}$ and Shc-Memo signalling in response to HRG in T47D cells, although in both cases PLC $\gamma$ was an important contributor. HRG $\beta 1$-Erb-B3 signalling also significantly enhances metastasis via PI3 kinase signalling, since mutation of its six YXXM PI3K p85-binding domains inhibited breast carcinoma cell motility, invasion, vascular intravasation and invasion (Smirnova et al., 2011).

Overall, EGFR/Erb-B signalling has been linked to all aspects of metastasis: stimulation of angiogenesis, alterations in cell-cell and cell-matrix adhesion, upregulation of proteases and other key molecules (CXCR4, CD44, specific integrins), vessel intravasation/ extravasation and organ-selective colonisation (Eccles, 2001) (Fig. 3). There is now a growing appreciation that bone-marrow-derived mesenchymal stem cells (MSC) are recruited to the stroma of developing tumours and also contribute to formation of the 'premetastatic niche'. Stimulation of MSC with tumour cell-derived TGF $\alpha$ simulated release of angiogenic factors and induced breast carcinoma cell migration; another example of mutual Erb-mediated tumour-host interactions involved in tumour progression (De Luca et al., 2011).

Dissemination to lymph nodes is a key factor in breast cancer staging, but increasingly identification of disseminated tumour cells (DTC) in the blood and in bone marrow aspirates is also being linked to poor prognosis. These cells frequently overexpress EGFRand Erb-B2 (even when the primary tumour is negative)(Braun et al., 2001). Such observations have led to the acceptance that dissemination may be a much earlier event than originally appreciated (Eccles and Paon, 2005) and that the Erb-B proteins, amongst others, may significantly contribute to tumour cell escape, motility and dissemination.

Fig. 3. Role of EGFR/Erb-B receptors and ligands in metastasis and organotropism. Most if not all of the Erb-B family have been linked to an increased probability of breast cancer metastasis and, in some cases to site-selective growth. At the primary tumour site, EGFR and Erb-B2 in particular regulate factors that promote angiogenesis and invasion. Protection from anoikis and motility contribute to the ability of tumour cells to survive in the circulation, and specific ligands promote extravasation through the specialised microvasculature of different organs. There is limited involvement in the early generation of 'pre-metastatic niches', but finally, tumour cells expressing EGFR or Erb- $B$ receptors respond to local growth factors to generate overt metastases. $O B=$ osteoblasts, $O C=$ osteoclasts. levels of TGFa

\section{Organotropism and site selectivity of metastasis}

The commonest site of breast cancer metastasis is the bone, and there is a well-described 'vicious cycle' involving both tumour and host cells that perpetuates tumour cell colonisation, metastasis development and bone destruction (Guise, 2010). Although there is reportedly no clear association between high levels of specific Erb-B receptors (or their ligands) in bone metastases - and indeed Erb-B2 seems to be under-represented - there is good evidence of a role for ligand-activated proteases in the bone microenvironment (Foley et al., 2010).

Seminal work by Massague's group deciphered the genetic determinants underlying key phases of metastasis in the MDAMB-231 breast carcinoma model: escape from the primary tumour, extravasation and growth at secondary sites. Sublines with tropism for specific sites (bone, lung, brain) were isolated and their key characteristics analysed. Osteoclast activity in the bone microenvironment is regulated by a balance between RANKL and osteoprotegerin (OPG). The presence of breast cancer cells upsets this balance, leading to a net increase in bone destruction via os-

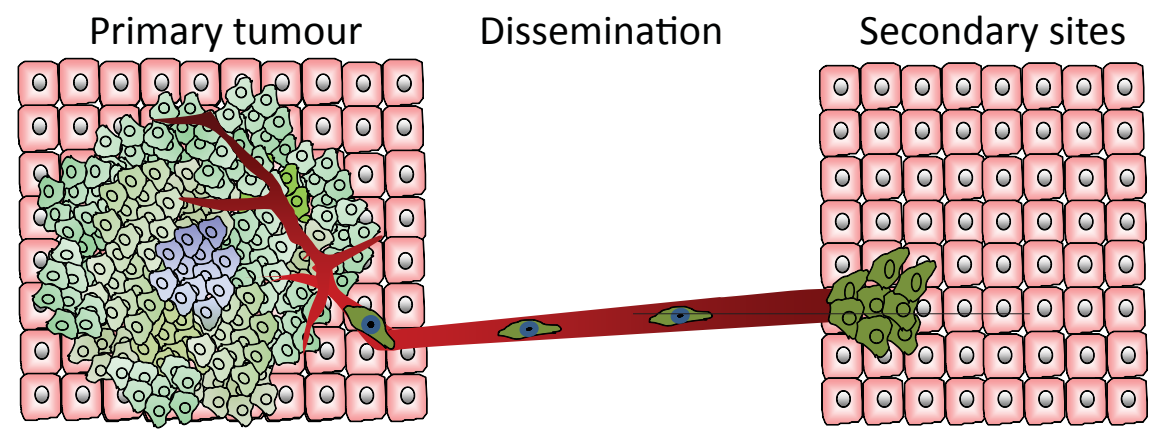
EGFR/Erb-B2 - protection from anoikis

AREG/EGF released by ADAMs from tumour cells (together with 7 Bone PTHrP) activate osteoblasts (OB). OB secrete RANKL and activate osteoclasts $(\mathrm{OC})$, which release EGFR ligands from stroma, stimulating tumour growth

Erb-B2+ cells show preferential localisation/growth in marrow

HB-EGF promotes extravasation across BBB Erb-B2/ErbB3 heterodimers respond to local NRGs Erb-B2 promotes outgrowth of micrometastases

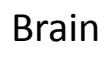

$$
\text { Erb-B2 promotes outgrowth of micrometastases }
$$

EREG promotes extravasation in lung microvasculature EGFR+ tumour cells proliferate in response to high levels of EGF and EREG

Lung

EGFR+ tumour cells proliferate in response to high

Liver 
teoclasts, and release of sequestered growth factors which in turn stimulate growth and invasion of the tumour (Kang et al., 2003).

Ligands such as EGF or AREG shed by tumour cells activate EGFR-expressing osteoblasts to secrete less OPG; simultaneously autocrine stimulation releases PTHrP from tumour cells to the same end, and the osteoblasts in turn release EGFR ligands and perpetuate the cycle of monocyte-derived osteoclast activation via RANKL or MCP and thus bone destruction (Foley et al., 2010). PTHrP has been recognised as one of the "metastasis virulence factors" within a bone metastasis gene signature. It transcriptionally regulates AREG and to a lesser extent TGF $\alpha$ and HB-EGF, and may also increase ligand shedding via ADAM17. MMP1 and ADAMTS-1, additional members of the 11-gene signature, also increase AREG shedding and bone metastasis. Although MDA$\mathrm{MB}-231$ represents an ER $\alpha$ negative breast cancer, since AREG is regulated by oestrogen, this pathway could be of more general significance in breast cancer. However, it remains to be seen whether EGFR inhibitors will have an impact, alone or in combination, against bone metastasis.

A degree of organotypic metastasis selection is determined by the ability of tumour cells to extravasate through the phenotypicallydistinct vasculature within specific organs. The bone marrow and liver vasculature is fenestrated and does not provide a significant barrier to tumour cell colonisation; however the lung endothelium has tight junctions and the blood-brain barrier (BBB) is even further specialised. EREG, together with COX-2, MMP-1 and ANGPTL4 has been linked to an enhanced capacity of breast tumour cells to extravasate in the lungs since together they can compromise the integrity of the pulmonary microvasculature. In contrast, HB-EGF,
COX2 and specifically the $\alpha 2,6$-sialyltransferase ST6GALNAC5 were strongly associated with breast cancer brain metastases (Bos et al., 2009) (Fig. 3).

The predilection of breast cancers expressing Erb-B oncogenes to metastasise to the brain may also be due to the fact that their cognate ligands (NRGs) are neural growth factors. It has been shown experimentally that Erb-B2 overexpression increases the outgrowth of breast cancer cells in the brain, rather than the initial seeding efficiency and formation of micrometastases (Palmieri et al., 2007). The co-association of CXCR4 and Erb-B2 may be linked to visceral metastases, and similarly cells overexpressing EGFR could respond to the high levels of ligands such as TGF $\alpha$ and EREG in liver and lung (Eccles and Welch, 2007) (Fig. 3).

\section{Therapy targeting the EGFR/Erb-B family}

EGFR and Erb-B2 have been the main receptors considered as targets for immunotherapeutic approaches in breast cancer, mainly via antibody-based therapies, but also in active immunisation and gene therapy protocols, as well as ligand-targeted toxin and antisense/RNAi approaches and anti-Erb-B2 vaccines (Ladjemi et al., 2010) (Table1; Fig. 4).

A novel means of inhibiting Erb-B expression and function is via HSP90 chaperone inhibitors such as 17-AAG and NVP-AUY922. HSP90 levels correlate with poor prognosis in breast cancer and Erb-B2 is a particularly sensitive 'client' protein, being highly dependent on HSP90 for its correct folding and cellular localisation. HSP72, a related chaperone, has also been shown to be essential for Erb-B2-driven oncogenesis in transgenic mouse models by

TABLE 1

\section{EXAMPLES OF THERAPIES TARGETING THE EGFR/ERB-B FAMILY}

\begin{tabular}{|c|c|c|c|}
\hline Agent & Type & Target(s) & Comments \\
\hline Trastuzumab (Herceptin) and T-DM1 & Humanised IgG1 monoclonal antibody & Erb-B2 juxtamembrane region (domain IV) & $\begin{array}{l}\text { Approved for Erb-B2+ MBC and node+ early stage disease. Also } \\
\text { conjugated to DM1, (maytansine toxin) for targeted delivery. Phase } \\
\text { III. Active in trastuzumab-resistant cells }\end{array}$ \\
\hline Pertuzumab (Omnitarg) & $\begin{array}{l}\text { Fully humanised IgG1 monoclonal } \\
\text { antibody }\end{array}$ & Erb-B2 dimerisation domain (II) & $\begin{array}{l}\text { Inhibits dimerisation with EGFR and Erb-B3. Phase III breast } \\
\text { cancer }\end{array}$ \\
\hline Cetuximab (Erbitux) & Chimaeric IgG1 monoclonal antibody & EGFR ECD & Little activity in EGFR+ breast cancer \\
\hline Panitumumab (Vectibix) & Fully human IgG2 monoclonal antibody & EGFR ECD & Little activity in EGFR+ breast cancer \\
\hline Ertumaxomab & Bispecific monoclonal antibody & Erb-B2 and FcyRI/III & Promotes ADCC via T cells. Phase II breast cancer \\
\hline Gefitinib (Iressa) & Reversible TKI (quinazoline) & EGFR kinase domain & Limited activity in breast cancer \\
\hline Erlotinib (Tarceva) & $\begin{array}{l}\text { Reversible TKI } \\
\text { (quinazoline) }\end{array}$ & EGFR kinase domain & Limited activity in breast cancer \\
\hline Lapatinib (Tykerb) & $\begin{array}{l}\text { Reversible TKI } \\
\text { 4-anilinoquinine }\end{array}$ & EGFR/Erb-B2 kinase domain & Response linked primarily to Erb-B2 overexpression. \\
\hline $\begin{array}{l}\text { Neratinib } \\
\text { (HKI-272) }\end{array}$ & Irreversible TKI & $\begin{array}{l}\text { Pan-Erb-B } \\
\text { kinase domain }\end{array}$ & $\begin{array}{l}\text { Active in cells with EGFR and Erb-B2 mutations. Phase I/II + } \\
\text { temsirolimus in Erb-B2+ or TNBC }\end{array}$ \\
\hline Afatinib (BIBW-2992) & Irreversible TKI & $\begin{array}{l}\text { EGFR/Erb-B2 } \\
\text { kinase domain }\end{array}$ & $\begin{array}{l}\text { Active in trastuzumab-resistant breast cancer. Plans to trial in } \\
\text { inflammatory BC and in several combinations }\end{array}$ \\
\hline $\begin{array}{l}\text { Canertinib } \\
(\mathrm{Cl}-1033)\end{array}$ & Irreversible TKI & $\begin{array}{l}\text { Pan-Erb-B } \\
\text { kinase domain }\end{array}$ & Phase II results poor in lung and ovarian cancer \\
\hline AEE788 & Reversible TKI & EGFR, Erb-B2 VEGFR & $\begin{array}{l}\text { Added benefit with letrozole in preclinical breast cancer models. } \\
\text { Phase } \mathrm{I} / \mathrm{Il} \text { in other cancer types }\end{array}$ \\
\hline $\begin{array}{l}\text { BMS-599626 } \\
(\text { AC480) }\end{array}$ & Reversible TKI & EGFR/Erb-B2 kinase domain & Inhibits EGFR-ErbB2 heterodimers. Phase I \\
\hline Arry-334543 & Reversible TKI & $\begin{array}{l}\text { EGFR/Erb-B2/B4 } \\
\text { kinase domain }\end{array}$ & Phase II in breast cancer \\
\hline MM-111 & Bispecific fusion protein & Blocks Erb-B3 ligand binding & Targets ErbB2-B3 heterodimers \\
\hline Tanespimycin (17-AAG) & Ansamycin & HSP90 chaperones & Targets ErbB2, AKT, VEGFR, ER $\alpha$. Phase III breast \\
\hline $\begin{array}{l}\text { Retaspimycin } \\
\text { (IPI-504) }\end{array}$ & Ansamycin & HSP90 chaperones & Targets ErbB2, AKT, VEGFR ER $\alpha$, Phase II breast \\
\hline NVP-AUY922 & Isoxazole resorcinol & HSP90 chaperones & Targets ErbB2, AKT, VEGFR, ER $\alpha$. Phase I/II breast \\
\hline BIIB 021 & Purine scaffold & HSP90 chaperones & Phase II in ER+ MBC + Exemestane \\
\hline
\end{tabular}


regulating senescence signalling pathways (Meng et al., 2011). Other key client proteins are also important in breast tumour development (e.g. ER $\alpha$ ) and progression, for example: AKT in cell survival and resistance to multiple agents; VEGF receptors in angiogenesis/lymphangiogenesis; FAK, Src and MET in invasion - to name but a few. HSP90 inhibitors induce depletion and proteasomal degradation of Erb-B2 and other client proteins in vitro and in vivo, resulting in potent antitumour and antiangiogenic activity in preclinical tumour models (Eccles et al., 2008), most notably in ER $\alpha+/ E r b-B 2+B T 474$ xenografts. Recent clinical trial data in MBC where patients had progressed on trastuzumab are very promising (Modi et al., 2011). In preclinical and clinical studies, trastuzumab labelled with positron-emitting isotopes has also been used to monitor responses as described later in this review.

\section{Inhibiting ligand binding/dimerisation}

The anti-EGFR antibody cetuximab has been tested in combination with a variety of standard chemotherapeutic agents in breast cancer but with little benefit and sometimes unacceptable skin toxicity. Cetuximab is a chimeric IgG1, whereas panitumumab is a fully human IgG2 anti-EGFR monoclonal antibody which has been less frequently evaluated in breast cancer (Burness et al., 2010).

Trastuzumab, a humanised anti-ErbB2 monoclonal antibody targeting the juxtamembrane region of the extracellular domain, has been more successful in clinical trials, particularly in combination with standard chemotherapy and in the adjuvant setting (Goel et al., 2011). This sensitisation to chemotherapy may involve downregulation of Mcl-1, an antiapoptotic protein and/or activation of PTEN which dephosphorylates AKT (a key survival signal) thereby promoting cell death. Trastuzumab is reportedly most active in tumours driven by Erb-B2 homodimers and is also effective in combination with antiendocrine therapies in ER+ tumours. Given the many key cellular functions activated downstream of Erb-B signalling, it is not surprising that trastuzumab (and other Erb-B-targeted therapies) also inhibit angiogenesis, which could contribute indirectly to tumour responses. Combinations of trastuzumab with bevacizumab, an antibody targeting the major angiogenic cytokine (VEGF) are also being trialled.

In addition to direct inhibition of Erb-B2 function, e.g. by promoting its internalisation and degradation, trastuzumab can promote antibody-directed cellular cytotoxicity (ADCC) mediated by natural killer (NK) cells. Interestingly (but unfortunately) an increase in the incidence of brain metastases has been observed in patients treated with trastuzumab. This may reflect both the fact that Erb-B2 positive tumours have a predilection for colonising the brain and because antibodies fail to cross the BBB effectively.

Pertuzumab is another humanised antibody that inhibits Erb-B2 heterodimerisation with other family members by binding to the dimerisation loop of the former (i.e a different site from trastuzumab). It has shown some promise in Erb-B2+ breast and ovarian cancer patients and is also being evaluated in combination with trastuzumab and chemotherapy (CLEOPATRAtrial) (Baselga and Swain, 2010). In general, Erb-B2 targeted therapies are only effective in cancers with gene amplification, and sensitive assays are needed to determine those eligible (e.g. HercepTest or Oncotype Dx). Antibodies to Erb-B2 have also been employed to measure expression levels in tumours and also to monitor responses to therapy using positron emission tomography (PET) or Erb-B2-targeted nanoparticles in $\mathrm{MRI}$ approaches, since they report non-invasively on the level of membrane-exposed receptor (Capala and Bouchelouche, 2010). Similarly, ELISA or dot-blot assays can be performed on plasma samples to monitor the levels of Erb-B2 ECD and also reportedly correlate with tumour levels in several studies.

Advances in antibody-based therapies include the targeting of

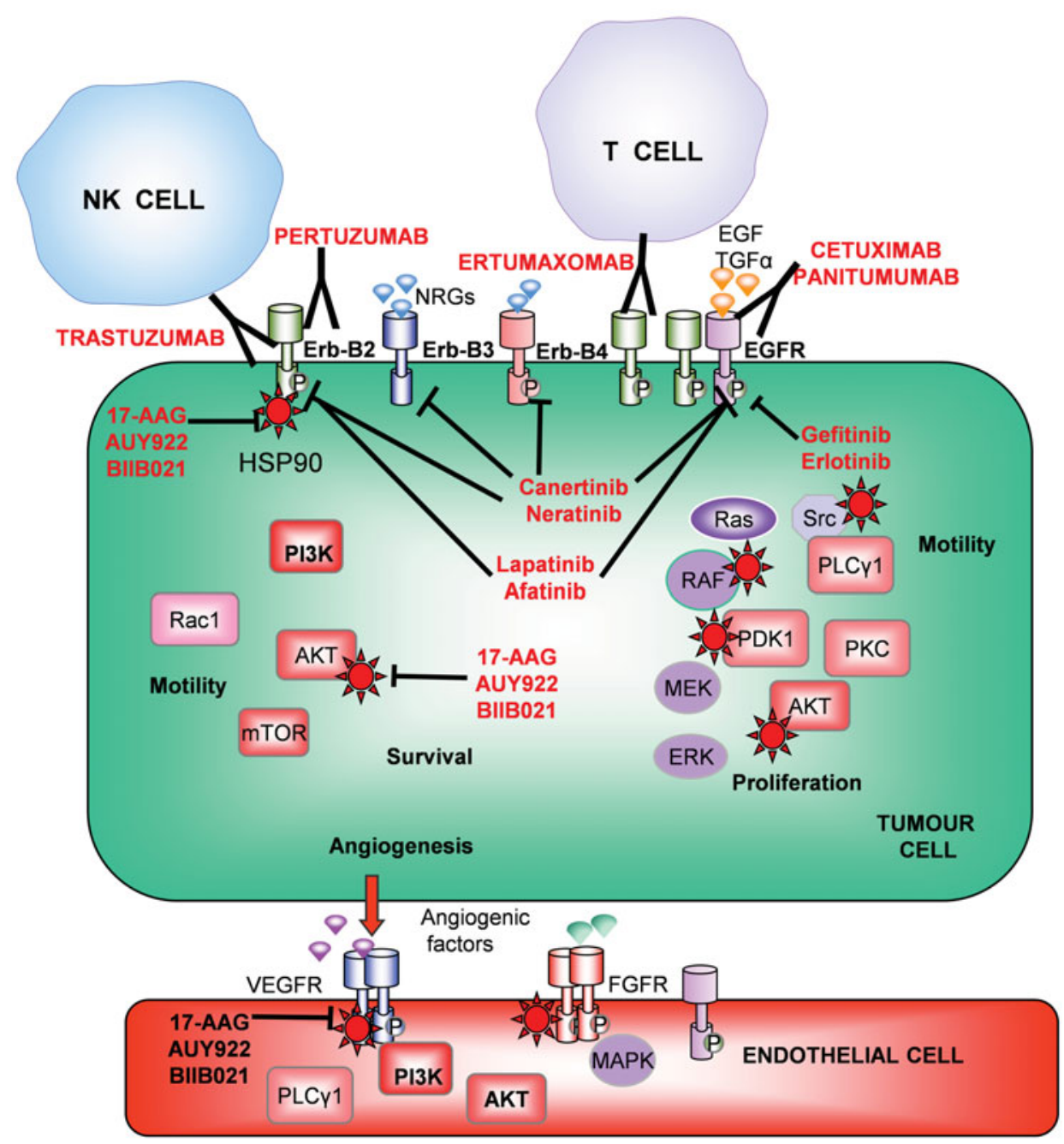

Fig. 4. Key EGFR/Erb-B signalling pathways and sites of action of therapeutic agents. The figure illustrates monoclonal antibodies, small molecule kinase inhibitors and other agents (e.g. chaperone inhibitors) and their mechanisms of action in breast cancer cells and the associated vasculature. 
prodrug activating enzymes or nanoparticles carrying cytotoxic payloads (Colombo et al., 2010). Recently, complexes of a compact human anti-Erb-B2 antibody and cytotoxic human pancreatic RNase have shown promise in vitro and in vivo in a rodent breast tumour model (Borriello et al., 2011). In experimental systems, it has been shown that using combinations of anti-Erb-B2 antibodies recognising different epitopes are more effective at inhibiting ligand-mediated invasion than single agents.

\section{Inhibiting kinase activity}

Several reversible and irreversible SMTKI with varying degrees of selectivity have been developed. These small molecule agents compete with ATP binding in the kinase domain of the receptor and inhibit downstream signalling. The most well known are the EGFR selective inhibitors erlotinib and gefitinib, the dual EGFR/Erb-B2 inhibitor lapatinib and the more recently developed irreversible inhibitor afatinib.

Gefitinib and erlotinib have shown little if any single agent activity in breast cancer, even in triple negative cases which often have high levels of EGFR. Several trials are underway where EGFR $\mathrm{TKI}$ are used in combination with other cytotoxic or molecularly targeted agents.

Lapatinib binds the ATP-binding pocket of both EGFR and ErbB2, preventing autophosphorylation, potentially limiting 'escape' or rapid development of resistance to monotherapies. Unlike trastuzumab, activation of the PI3K pathway does not seem to impair its efficacy. It has been used alone and in combination with both cytotoxic and molecularly targeted agents. Combination with trastuzumab improved median progression-free survival and reduced the risk of disease progression in a phase III trial of heavily pre-treated patients and it has also been approved for use in those who have failed trastuzumab. Most responses have been seen in Erb-B2-positive patients, with little or no benefit in patients with triple negative or EGFR-positive cancers (Burness et al., 2010). Neratinib is another orally active agent which irreversibly inhibits the kinase activity of EGFR, Erb-B2 and Erb-B4 which has shown promise in previously untreated and also trastuzumab-resistant breast cancers (Colombo et al., 2010). It is also being trialled in combination with paclitaxel, capecitebine and vinorelbine.

\section{Links between Erb-B signalling and resistance to therapy}

EGFR activation has been linked to resistance to the antiendocrine agent tamoxifen, possibly via phosphorylation of AIB1, an $\mathrm{ER} \alpha$ co-activator which can result in mitogenic (rather than inhibitory) activity. Phosphorylation of $\mathrm{ER} \alpha$ (which can be achieved by several upstream kinases including Erb-B2) can also lead to oestrogen-independent transcription of ER $\alpha$ targets, also resulting in resistance to tamoxifen. There is cross talk between $\mathrm{ER} \alpha, \mathrm{c}-\mathrm{Src}$, EGFR, and STAT5b in ER+ breast cancer cells and increased EGFR and $c$-Src signaling is associated with tamoxifen resistance. Constitutively active STAT5b increased DNA synthesis and conferred tamoxifen resistance in $\mathrm{ER}+$ human breast carcinoma cell lines. Cells exposed to a pure anti-oestrogen (fulvestrant) acquired a resistant phenotype which included elevated expression and phosphorylation of EGFR and Erb-B2, together with TGF $\alpha$ and AREG expression. More recently, fulvestrant has also been shown to upregulate Erb-B3 and/or Erb-B4 and to sensitise cells to
NRG $\beta 1$ (Hutcheson et al., 2011). It is possible, therefore, that mitogenic autocrine signalling via any or all of the Erb-B receptors may subsume the role of oestrogen during breast cancer progression.

EGFR activation stimulates signalling via AKT and ERK, and has been linked to multidrug resistance via upregulation of MRP1,3,5 and 7. Erb-B3 (and also Erb-B4) has also been linked to resistance to anti-endocrine therapy (Sutherland, 2011) and to paclitaxel, reportedly by upregulating survivin via the PI3K-AKTmTOR pathway. Amphiregulin expression has been associated with resistance to cisplatin in MCF7 cells and in patients via enhanced EGFR, AKT and ERK1 activation. EGFR and Erb-B2 activation may also be involved with resistance to radiotherapy, since both are upregulated/activated following exposure to ionising radiation.

Several mechanisms of acquired resistance to EGFR/Erb-B2 targeted therapies have been described, including subversion of trastuzumab binding to Erb-B2 by shed p95 ECD fragments (Arribas et al., 2011); a switch to alternative signaling via other Erb-B family members (notably Erb-B3), alternative RTK such as c-MET, IGF1R or EphA2, and finally activated downstream signalling elements (e.g. PI3 kinase-AKT-FOX1A) for example via loss of PTEN or by PIK3CA mutations. (Garrett and Arteaga, 2011). In the early days, the development of host antibodies against the therapeutic antibody could neutralise their activity upon repeat administration. However this has now largely been overcome by the development of humanised (or fully human) therapeutic antibodies.

In addition, there is evidence of primary resistance (or lack of sensitivity) in many patients, in spite of the fact that their tumours overexpress the target receptor, although the reasons for this - which are likely to be many and various - are less well understood. One mechanism may involve negative feedback loops in cases where trastuzumab fails to abolish Erb-B2 phosphorylation. This may occur due to trans-phosphorylation by other Erb-B receptors, following an AKT-dependent ADAM17-mediated release of Erb-B ligands (Gijsen et al., 2010). Also, c-SRC has recently been identified as a common mediator of multiple trastuzumab resistance pathways in both acquired and de novo trastuzumab-resistant cells, involving dephosphorylation by PTEN. Increased c-SRC activation conferred resistance in breast cancer cells and correlated with trastuzumab refractoriness in patients. Targeting C-SRC re-sensitized cells to trastuzumab and eliminated trastuzumab-resistant tumours in vivo, suggesting a potential clinical application of this strategy (Zhang et al., 2011).

Molecular mechanisms of resistance to small molecule inhibitors generally differ from those linked to refractoriness to antibody therapy. In the former case, mutations in the kinase domain of EGFR emerge which reduce the binding affinity SMTKI, whereas in the latter case, as described above, downregulation of the primary molecular target, a shift to non-inhibitable dimers (such as Erb-B2-IGF1R) or a short-circuit of the downstream signalling pathways is more common. Other reported resistance mechanisms include a mutation in exon 21 of the HER2 gene that encodes a protein with reduced affinity for trastuzumab and upregulation of MUC4, a membrane-bound glycoprotein which binds Erb-B2 and can compete with trastuzumab binding.

Future strategies will need to include rational combinations of therapeutic agents to overcome (or pre-empt) resistance. Research laboratories developing new targeted agents are deliberately generating cells with acquired resistance in order to understand future likely escape mechanisms of cancers in the clinic. These 
cells are then subjected to microarray or to proteomic analysis to uncover the mechanisms of resistance. If this reveals a mutated target (as in the case of EGFR), then screens can be performed to identify new compounds which can bind the altered conformation; alternatively, 'synthetic lethal' screens of either known therapeutic agents or siRNA libraries can be used to identify new vulnerabilities (Achilles' heels) in the resistant cells which may be exploitable as targets. One good example is the multikinase inhibitor dasatinib, which shows synergistic anti-proliferative activity with trastuzumab in Erb-B2 expressing BT474 human breast carcinoma cells both in vitro and in vivo (Seoane et al., 2010). Since one of the kinase targets of dasatinib is c-SRC, this protocol may also help to prevent development of resistance as outlined in the previous section.

\section{Cancer stem-like cells (CSC)}

Cells which express one or more supposed markers of stem cells (e.g. $\mathrm{CD}_{4} 4^{+} / \mathrm{CD} 24^{-} \mathrm{ALDH} 1^{+}$and with their phenotypic characteristics (self-renewal capacity, anchorage-independent growth, pluripotency) have been isolated from mammary glands and breast cancers. It has been proposed that such cells may represent the true seeds of cancer, contributing to drug resistance (due to expression of drug efflux pumps and low proliferative rate) and relapse. Normal breast stem cells show a 'basal' phenotype, hence breast CSC may be endocrine resistant because they express low levels of $E R \alpha$. Ligand-induced EGFR signalling is required to support the clonogenicity of CSC derived from cancers and DCIS in soft agar, and overexpression of Erb-B2 in MEC increases the proportion of cells with CSC properties. Normal breast epithelial stem cells are highly dependent on EGFR and other RTK, raising the possibility that their increased expression in endocrine-resistant breast cancers reflects an increased proportion of CSCs selected for by endocrine therapies. Several studies show that breast CSCs are ER $\alpha+/ E G F R+/ E r b-B 2+$, supporting this view (O'Brien et al., 2011). These observations suggest that Erb-B2 and/or EGFR inhibitors could target the CSC population, and indeed one small study with the dual inhibitor lapatinib suggested that it reduced the frequency of CD44+/CD24- cells in breast cancer biopsies (Schmidt, 2008). Further studies are required to establish whether stem-like cells, perhaps shed early in cancer progression, may remain dormant and refractory to therapy until reactivated, when they may contribute to treatment relapse and metastasis. There is no doubt that we will need to pay more attention to the genotypic phenotypic properties of pre-existing micrometastases if we are ever to provide robust and sustained control of disseminated breast cancer.

\section{Acknowledgements}

SAE is funded by The Institute of Cancer Research and Cancer Research UK programme grant number C309/A8274 awarded to The Cancer Therapeutics Unit (Director, Professor Paul Workman). The ICR acknowledges NHS funding to the NIHR Biomedical Research Centre. I wish to acknowledge the many colleagues, past and present, with whom I have collaborated over the years on aspects of Erb-B biology and translational research, including the late Dr Christopher Dean, erstwhile Head of the Section of Immunology at ICR who pioneered our research on monoclonal antibodies to Erb-B2 and EGFR. I regret that due to space constraints it has not been possible to include all of the relevant references of scientists and clinicians all over the world who have contributed to our current understanding of this important receptor family and their exploitation for patient benefit.

\section{References}

ALEXI, X., BERDITCHEVSKI, F. and ODINTSOVA, E. (2011). The effect of cell-ECM adhesion on signalling via the ErbB family of growth factor receptors. Biochem Soc Trans 39: 568-573.

ARRIBAS, J., BASELGA, J., PEDERSEN, K. and PARRA-PALAU, J.L. (2011). p95HER2 and breast cancer. Cancer Res 71: 1515-1519.

BASELGA, J. and SWAIN, S.M. (2010). CLEOPATRA: a phase III evaluation of pertuzumab and trastuzumab for HER2-positive metastatic breast cancer. Clin Breast Cancer 10: 489-491.

BLOBEL, C.P., CARPENTER, G. and FREEMAN, M. (2009). The role of protease activity in ErbB biology. Exp Cell Res 315: 671-682.

BORRIELLO, M., LACCETTI, P., TERRAZZANO, G., D'ALESSIO, G. and DE LORENZO, C. (2011). A novel fully human antitumour immunoRNase targeting ErbB2-positive tumours. Br J Cancer 104: 1716-1723.

BOS, P.D., ZHANG, X.H., NADAL, C., SHU, W., GOMIS, R.R., NGUYEN, D.X., MINN A.J., VAN DE VIJVER, M.J., GERALD, W.L., FOEKENS, J.A. et al., (2009). Genes that mediate breast cancer metastasis to the brain. Nature 459: 1005-1009.

BRAUN, S., SCHLIMOK, G., HEUMOS, I., SCHALLER, G., RIETHDORF, L., RIETHMULLER, G. and PANTEL, K. (2001). ErbB2 overexpression on occult metastatic cells in bone marrow predicts poor clinical outcome of stage I-III breast cancer patients. Cancer Res 61: 1890-1895.

BURGA, L.N., HU, H., JUVEKAR, A., TUNG, N.M., TROYAN, S.L., HOFSTATTER, E.W. and WULF, G.M. (2011). Loss of BRCA1 leads to an increase in epidermal growth factor receptor expression in mammary epithelial cells, and epidermal growth factor receptor inhibition prevents estrogen receptor-negative cancers in BRCA1-mutant mice. Breast Cancer Res 13: R30. doi:10.1186/bcr2850

BURNESS, M.L., GRUSHKO, T.A. and OLOPADE, O.I. (2010). Epidermal growth factor receptor in triple-negative and basal-like breast cancer: promising clinical target or only a marker? Cancer J 16: 23-32.

CAPALA, J. and BOUCHELOUCHE, K. (2010). Molecular imaging of HER2-positive breast cancer: a step toward an individualized 'image and treat' strategy. Curr Opin Oncol 22: 559-566.

CITRI, A. and YARDEN, Y. (2006). EGF-ERBB signalling: towards the systems level. Nat Rev Mol Cell Biol 7: 505-516.

COHEN, S. (1997). EGF and its receptor: historical perspective. Introduction. J Mam mary Gland Biol Neoplasia 2: 93-96.

COLOMBO, M., CORSI, F., FOSCHI, D., MAZZANTINI, E., MAZZUCCHELLI, S., MORASSO, C., OCCHIPINTI, E., POLITO, L., PROSPERI, D., RONCHI, S. et al., (2010). HER2 targeting as a two-sided strategy for breast cancer diagnosis and treatment: Outlook and recent implications in nanomedical approaches. Pharmacol Res 62: 150-165.

DAWSON, S.J., PROVENZANO, E. and CALDAS, C. (2009). Triple negative breast cancers: clinical and prognostic implications. Eur J Cancer 45 Suppl 1: 27-40.

DE LUCA, A., GALLO, M., ALDINUCCI, D., RIBATTI, D., LAMURA, L., D'ALESSIO, A., DE FILIPPI, R., PINTO, A. and NORMANNO, N. (2011). Role of the EGFR ligand/receptor system in the secretion of angiogenic factors in mesenchymal stem cells. J Cell Physiol 226: 2131-2138.

DENARDO, D.G., CUBA, V.L., KIM, H., WU, K., LEE, A.V. and BROWN, P.H. (2007) Estrogen receptor DNA binding is not required for estrogen-induced breast cell growth. Mol Cell Endocrinol 277: 13-25.

ECCLES, S.A. (2001). The role of c-erbB-2/HER2/neu in breast cancer progression and metastasis. J Mammary Gland Biol Neoplasia 6: 393-406.

ECCLES, S.A., MASSEY, A., RAYNAUD, F.I., SHARP, S.Y., BOX, G., VALENTI, M., PATTERSON, L., DE HAVEN BRANDON, A., GOWAN, S., BOXALL, F. et al., (2008). NVP-AUY922: a novel heat shock protein 90 inhibitor active against xenograft tumor growth, angiogenesis, and metastasis. Cancer Res 68: 2850-2860.

ECCLES, S.A. and PAON, L. (2005). Breast cancer metastasis: when, where, how? Lancet 365: 1006-1007.

ECCLES, S.A. and WELCH, D.R. (2007). Metastasis: recent discoveries and novel treatment strategies. Lancet 369: 1742-1757.

FOLEY, J., NICKERSON, N.K., NAM, S., ALLEN, K.T., GILMORE, J.L., NEPHEW, K.P. and RIESE, D.J., 2ND. (2010). EGFR signaling in breast cancer: bad to the bone. Semin Cell Dev Biol 21: 951-960.

GARRETT, J.T. and ARTEAGA, C.L. (2011). Resistance to HER2-directed antibod- 
ies and tyrosine kinase inhibitors: Mechanisms and clinical implications. Cancer Biol Ther 11.

GATZA, M.L., KUNG, H.N., BLACKWELL, K.L., DEWHIRST, M.W., MARKS, J.R. and CHI, J.T. (2011). Analysis of tumor environmental response and oncogenic pathway activation identifies distinct basal and luminal features in HER2-related breast tumor subtypes. Breast Cancer Res 13: R62. doi:10.1186/bcr2899

GIJSEN, M., KING, P., PERERA, T., PARKER, P.J., HARRIS, A.L., LARIJANI, B. and KONG, A. (2010). HER2 phosphorylation is maintained by a PKB negative feedback loop in response to anti-HER2 herceptin in breast cancer. PLoS Biol 8: e1000563.

GOEL, S., CHIRGWIN, J., FRANCIS, P., STUART-HARRIS, R., DEWAR, J., MILESHKIN, L., SNYDER, R., MICHAEL, M. and KOCZWARA, B. (2011). Rational use of trastuzumab in metastatic and locally advanced breast cancer: Implications of recent research. Breast 20: 101-110.

GRASSIAN, A.R., SCHAFER, Z.T. and BRUGGE, J.S. (2011). ErbB2 stabilizes epidermal growth factor receptor (EGFR) expression via Erk and Sprouty2 in extracellular matrix-detached cells. J Biol Chem 286: 79-90.

GUISE, T. (2010). Examining the metastatic niche: targeting the microenvironment. Semin Oncol 37 Suppl 2: S2-S14.

HIGASHIYAMA, S., IWABUKI, H., MORIMOTO, C., HIEDA, M., INOUE, H. and MATSUSHITA, N. (2008). Membrane-anchored growth factors, the epidermal growth factor family: beyond receptor ligands. Cancer Sci 99: 214-220.

HUTCHESON, I.R., GODDARD, L., BARROW, D., MCCLELLAND, R.A., FRANCIES, H.E., KNOWLDEN, J.M., NICHOLSON, R.I. and GEE, J.M. (2011). Fulvestrantinduced expression of ErbB3 and ErbB4 receptors sensitizes oestrogen receptorpositive breast cancer cells to heregulin beta1. Breast Cancer Res 13: R29. doi:10.1186/bcr2848

JIN, Q. and ESTEVA, F.J. (2008). Cross-talk between the ErbB/HER family and the type I insulin-like growth factor receptor signaling pathway in breast cancer. $J$ Mammary Gland Biol Neoplasia 13: 485-498.

JONES, F.E. (2008). HER4 intracellular domain (4ICD) activity in the developing mammary gland and breast cancer. JMammary Gland Biol Neoplasia 13:247-258.

KANG, Y., SIEGEL, P.M., SHU, W., DROBNJAK, M., KAKONEN, S.M., CORDONCARDO, C., GUISE, T.A. and MASSAGUE, J. (2003). A multigenic program mediating breast cancer metastasis to bone. Cancer Cell 3: 537-549.

KENNY, P.A. and BISSELL, M.J. (2007). Targeting TACE-dependent EGFR ligand shedding in breast cancer. J Clin Invest 117: 337-345.

LADJEMI, M.Z., JACOT, W., CHARDES, T., PELEGRIN, A. and NAVARRO-TEULON, I. (2010). Anti-HER2 vaccines: new prospects for breast cancer therapy. Cancer Immunol Immunother 59: 1295-1312.

MA, L., HUET, E., SEROVA, M., BERTHOIS, Y., CALVO, F., MOURAH, S. and MENASHI, S. (2010). Antisense inhibition of amphiregulin expression reduces EGFR phosphorylation in transformed human breast epithelial cells. Anticancer Res 30: 2101-2016.

MCINTYRE, E., BLACKBURN, E., BROWN, P.J., JOHNSON, C.G. and GULLICK, W.J. (2010). The complete family of epidermal growth factor receptors and their ligands are co-ordinately expressed in breast cancer. Breast Cancer Res Treat 122: $105-110$

MENG, L., HUNT, C., YAGLOM, J.A., GABAI, V.L. and SHERMAN, M.Y. (2011). Heat shock protein Hsp72 plays an essential role in Her2-induced mammary tumorigenesis. Oncogene 30: 2836-2845.

MODI, S., STOPECK, A., LINDEN, H., SOLIT, D., CHANDARLAPATY, S., ROSEN, N., D'ANDREA, G., DICKLER, M., MOYNAHAN, M.E., SUGARMAN, S. et al., (2011). HSP90 Inhibition Is Effective in Breast Cancer: A Phase II Trial of Tanespimycin (17-AAG) Plus Trastuzumab in Patients with HER2-Positive Metastatic Breast Cancer Progressing on Trastuzumab. Clin Cancer Res 17:5132-5139.

O'BRIEN, C.S., FARNIE, G., HOWELL, S.J. and CLARKE, R.B. (2011). Breast cancer stem cells and their role in resistance to endocrine therapy. Horm Cancer2: 91-103.

PALMIERI, D., BRONDER, J.L., HERRING, J.M., YONEDA, T., WEIL, R.J., STARK A.M., KUREK, R., VEGA-VALLE, E., FEIGENBAUM, L., HALVERSON, D. et al. (2007). Her-2 overexpression increases the metastatic outgrowth of breast cancer cells in the brain. Cancer Res 67: 4190-4198.

PRENZEL, N., ZWICK, E., LESERER, M. and ULLRICH, A. (2000). Tyrosine kinase signalling in breast cancer. Epidermal growth factor receptor: convergence point for signal integration and diversification. Breast Cancer Res 2: 184-190.

PROCTER, M., SUTER, T.M., DE AZAMBUJA, E., DAFNI, U., VAN DOOREN, V., MUEHLBAUER, S., CLIMENT, M.A., RECHBERGER, E., LIU, W.T., TOI, M. et al., (2010). Longer-term assessment of trastuzumab-related cardiac adverse events in the Herceptin Adjuvant (HERA) trial. J Clin Oncol 28: 3422-3428.

SAHIN, U., WESKAMP, G., KELLY, K., ZHOU, H.M., HIGASHIYAMA, S., PESCHON, J., HARTMANN, D., SAFTIG, P. and BLOBEL, C.P. (2004). Distinct roles for ADAM10 and ADAM17 in ectodomain shedding of six EGFR ligands. $J$ Cell Biol 164: 769-779.

SCHMIDT, C. (2008). Lapatinib study supports cancer stem cell hypothesis, encourages industry research. J Natl Cancer Inst 100: 694-695.

SCHULZE, W.X., DENG, L. and MANN, M. (2005). Phosphotyrosine interactome of the ErbB-receptor kinase family. Mol Syst Biol 1: 20050008.

SEOANE, S., MONTERO, J.C., OCANA, A. and PANDIELLA, A. (2010). Effect of multikinase inhibitors on caspase-independent cell death and DNA damage in HER2-overexpressing breast cancer cells. J Natl Cancer Inst 102: 1432-1446.

SHI, F., TELESCO, S.E., LIU, Y., RADHAKRISHNAN, R. and LEMMON, M.A. (2010) ErbB3/HER3 intracellular domain is competent to bind ATP and catalyze autophosphorylation. Proc Natl Acad Sci U S A 107: 7692-7697.

SMIRNOVA, T., ZHOU, Z.N., FLINN, R.J., WYCKOFF, J., BOIMEL, P.J., POZZUTO, M., CONIGLIO, S.J., BACKER, J.M., BRESNICK, A.R., CONDEELIS, J.S. et al., (2011). Phosphoinositide 3-kinase signaling is critical for ErbB3-driven breast cancer cell motility and metastasis. Oncogene. doi:10.1038/onc.2011.275

SORLIE, T. (2004). Molecular portraits of breast cancer: tumour subtypes as distinct disease entities. Eur J Cancer 40: 2667-2675.

STERN, D.F. (2008). ERBB3/HER3 and ERBB2/HER2 duet in mammary development and breast cancer. J Mammary Gland Biol Neoplasia 13: 215-223.

STERNLICHT, M.D. and SUNNARBORG, S.W. (2008). The ADAM17-amphiregulinEGFR axis in mammary development and cancer. $J$ Mammary Gland Bio Neoplasia 13: 181-194.

SUNDVALL, M., ILJIN, K., KILPINEN, S., SARA, H., KALLIONIEMI, O.P. and ELENIUS, K. (2008). Role of ErbB4 in breast cancer. J Mammary Gland Biol Neoplasia 13: 259-268.

SUTHERLAND, R.L. (2011). Endocrine resistance in breast cancer: new roles for ErbB3 and ErbB4. Breast Cancer Res 13: 106. doi:10.1186/bcr2878

SUTTON, L.M., HAN, J.S., MOLBERG, K.H., SARODE, V.R., CAO, D., RAKHEJA, D., SAILORS, J. and PENG, Y. (2010). Intratumoral expression level of epidermal growth factor receptor and cytokeratin $5 / 6$ is significantly associated with nodal and distant metastases in patients with basal-like triple-negative breast carcinoma. Am J Clin Pathol 134: 782-787.

VAN LAERE, S.J., VAN DER AUWERA, I., VAN DEN EYNDEN, G.G., VAN DAM, P., VAN MARCK, E.A., VERMEULEN, P.B. and DIRIX, L.Y. (2007). NF-kappaB activation in inflammatory breast cancer is associated with oestrogen receptor downregulation, secondary to EGFR and/or ErbB2 overexpression and MAPK hyperactivation. Br J Cancer 97: 659-669.

ZHANG, S., HUANG, W.C., LI, P., GUO, H., POH, S.B., BRADY, S.W., XIONG, Y., TSENG, L.M., LI, S.H., DING, Z. et al., (2011). Combating trastuzumab resistance by targeting SRC, a common node downstream of multiple resistance pathways. Nat Med 17: 461-469. 


\section{Further Related Reading, published previously in the Int. J. Dev. Biol.}

Molecular mechanisms of lymphangiogenesis in development and cancer Imke Albrecht and Gerhard Christofori

Int. J. Dev. Biol. (2011) 55: 483-494

\section{Evolution of angiogenesis}

Ramón Muñoz-Chápuli

Int. J. Dev. Biol. (2011) 55: 345-351

Epithelial-Mesenchymal Transitions in development and disease: old views and new perspectives M. Angela Nieto

Int. J. Dev. Biol. (2009) 53: 1541-1547

Cadherin-mediated cell-cell adhesion and tissue segregation in relation to malignancy

Ramsey A. Foty and Malcolm S. Steinberg

Int. J. Dev. Biol. (2004) 48: 397-409

Expression of c-ets-1 and uPA genes is associated with mammary epithelial cell tubulogenesis or neoplastic scattering A Delannoy-Courdent, W Fauquette, X F Dong-Le Bourhis, B Boilly, B Vandenbunder and X Desbiens

Int. J. Dev. Biol. (1996) 40: 1097-1108

$$
5 \text { yr ISI Impact Factor }(2010)=2.961
$$

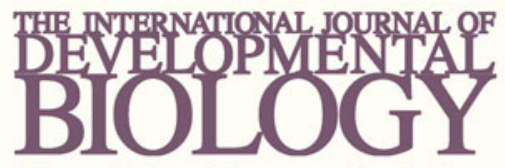

Volume 54 Nos. $6 / 7$
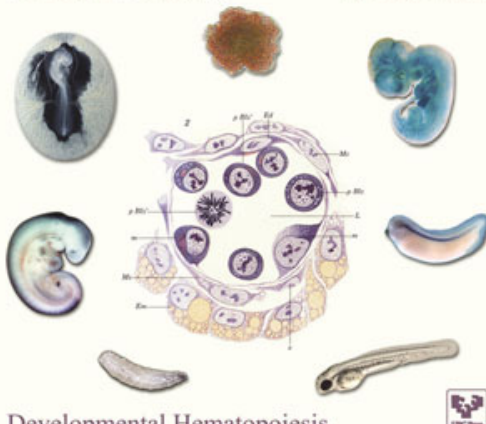

Developmental Hematopoiesis
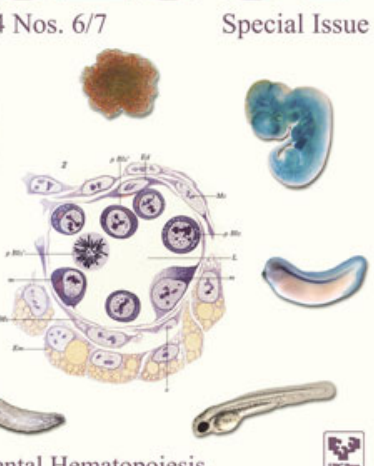

F
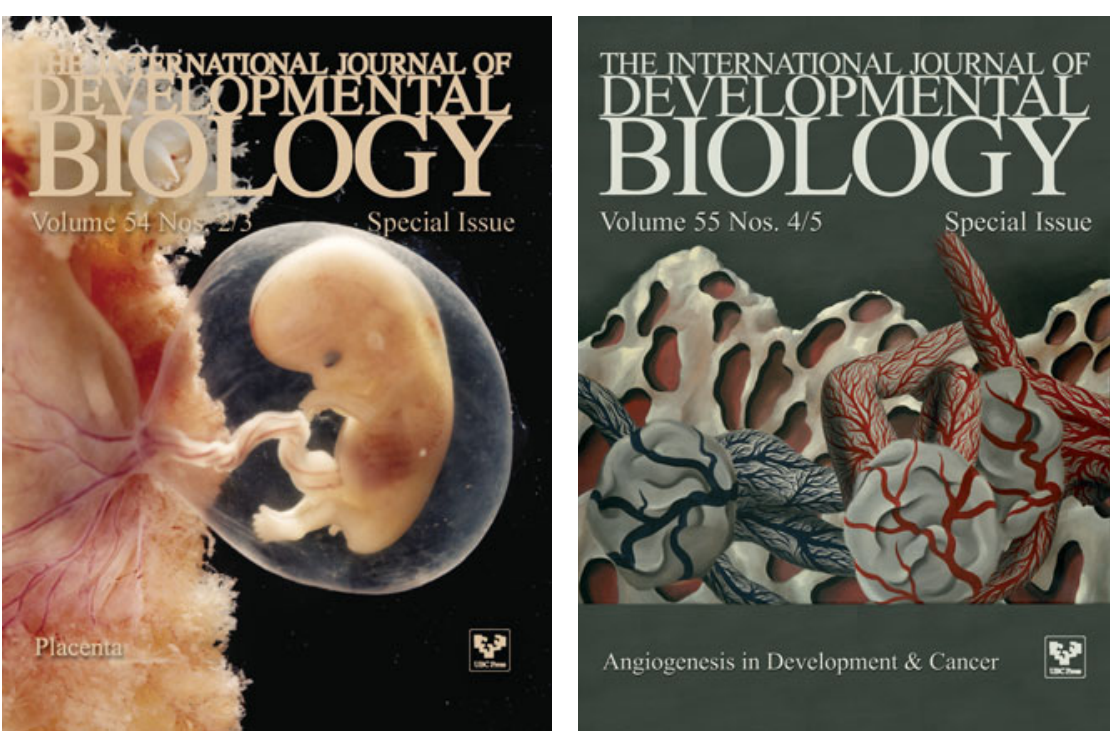